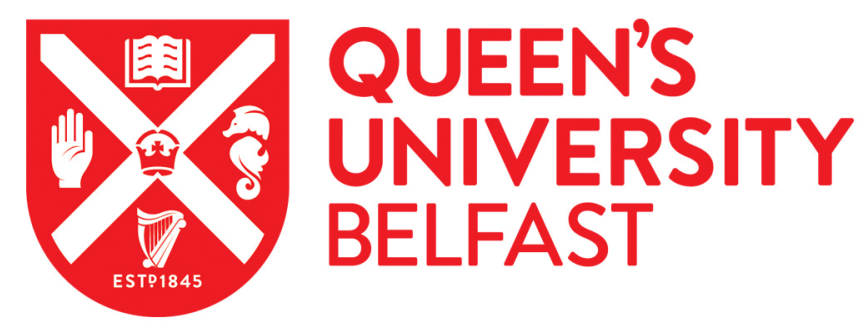

\title{
Extending the Two Process Model of Burnout in Child Protection Workers: The Role of Resilience in Mediating Burnout via Organizational Factors of Control, Values, Fairness, Reward, Workload and Community Relationships
}

McFadden, P., Mallet, J., \& Leiter, M. (2017). Extending the Two Process Model of Burnout in Child Protection Workers: The Role of Resilience in Mediating Burnout via Organizational Factors of Control, Values, Fairness, Reward, Workload and Community Relationships. Stress and Health. https://doi.org/10.1002/smi.2763

Published in:

Stress and Health

Document Version:

Peer reviewed version

Queen's University Belfast - Research Portal:

Link to publication record in Queen's University Belfast Research Portal

Publisher rights

(C) 2017 Wiley. This work is made available online in accordance with the publisher's policies. Please refer to any applicable terms of use of the publisher.

\section{General rights}

Copyright for the publications made accessible via the Queen's University Belfast Research Portal is retained by the author(s) and / or other copyright owners and it is a condition of accessing these publications that users recognise and abide by the legal requirements associated with these rights.

Take down policy

The Research Portal is Queen's institutional repository that provides access to Queen's research output. Every effort has been made to ensure that content in the Research Portal does not infringe any person's rights, or applicable UK laws. If you discover content in the Research Portal that you believe breaches copyright or violates any law, please contact openaccess@qub.ac.uk. 
Extending the Two Process Model of Burnout in Child Protection Workers: The Role of Resilience in Mediating Burnout via Organizational Factors of Control, Values, Fairness, Reward, Workload and Community Relationships

Abstract Burnout has been disproportionally reported in child-protection social work. This paper presents data from 162 child-protection staff in Northern-Ireland, assessed for burnout using the Maslach Burnout Inventory. Path models were estimated, based on an extension of the Two Process Demands and Values model (Leiter, 2008) to include additional measures of resilience using the Resilience Scale-14, as well as Perceived Rewards and Sense of Community from the Areas of Work Life Scale AWLS (Leiter, 2008). Optimal model fit was achieved by modelling Resilience as a mediator of the relationship between organisational factors of Control and Value Congruence and burnout. Resilience also directly predicted Emotional Exhaustion $(\beta=-.23, p<.005)$ and Personal Accomplishment $(\beta=.46, p<.001)$. Workload was the strongest direct predictor of Emotional Exhaustion $(\beta=-.54, p<.001)$. Adding Perceived Rewards to extend the Two Process Model resulted in moderate associations with Control $(\beta=.44, p<.001)$, Workload $(\beta=.26, p<.005)$, Fairness $(\beta$ $=.40, p<.001)$ and Values $(\beta=.32, p<.001)$. In the final model, Resilience is modelled as both an outcome of some organisational factors whilst also making a unique direct contribution to explaining burnout alongside other organisational factors. Other pathways and mediating relationships are reported and further research directions discussed.

\section{Introduction}

Child protection social work is acknowledged as a stressful and demanding occupation with high levels of staff turnover and concerning levels of inexperienced staff in front line practice (Healy et al., 2009; McGowan, et al., 2009; McFadden, et al., 2014). This is problematic as the profession is tasked with protecting the most vulnerable in society from abuse, neglect and significant harm. Increased pressure is added to this sector in recent times with a litany of Serious Case Reviews 
(SCRs) in the UK that point to failure to prevent child abuse and child death tragedies from occurring. Often SCRs and Inquiries draw on conclusions around systemic and professional shortcomings that fall short of protecting children. Common factors include references of professional 'blindness' to more deep seated systemic failings (Brandon et al., 2010) that may include the organizational culture and climate (Glisson et al., 2012). Parton (2014, p 11) maps four decades of child protection in the UK and provides a critical analysis of a growing 'politics of outrage' whereby the perpetrator of child abuse and fatalities tend not to be the focus of responsibility but blame often rests with professionals, particularly social workers and the administration of the child protection system itself. Concern therefore focuses on how to improve failings in the child protection system, as opposed to addressing child abuse in society.

Using an extension of the Two Process model (Leiter, 2008), the current paper aims to provide insight into organizational factors that potentially impact on burnout feelings of emotional exhaustion, depersonalisation and personal accomplishment within a social work context and seeks to locate individual resilience within this framework to better explain job burnout.

\section{Relevance of Resilience to Burnout and their Definitions}

What is it that makes some workers seem more resilient to the high demands of this occupation? Why do some social workers seem to survive and thrive in these conditions whilst others burn out? Resilience theory may offer an explanation. According to Wagnild \& Young (1993) resilience is 'state' and not 'trait', meaning that levels of resilience are altered according to the social context. Wagnild (2009) defines resilience as a process in reaction to adversity that enables individuals to maintain equilibrium and find meaning that enables them to survive difficult and challenging life events.

"Individuals who are resilient regain balance and keep going despite adversity and find meaning amidst confusion and turmoil.” (Wagnild, 2009a p. 12). 
Maslach \& Leiter (2008 p. 498) proposed the continuum concept between "burnout and job engagement" that supports the 'state' theory by Wagnild (2009a) which contends that one's reaction to adversity is not a trait based phenomenon but instead it is a 'state' and is context specific and therefore reliant on resilience building protective factors being present. Burnout is considered to be an 'adverse' life event and is defined as follows. "A syndrome of emotional exhaustion, depersonalization, and reduced personal accomplishment that can occur among individuals who do ‘people work'.” (Maslach \& Jackson, 1986 p. 1).

Burnout may be defined as a stress related phenomenon with the potential to impact on somatic aspects of health. For example, 'headaches, gastrointestinal disorders, muscle tension, hypertension, cold and flu episodes and sleep disorder' (Maslach \& Leiter 2008 p. 499). It is also related to mental distress states that are categorised under the title of "Job Related Neurasthenia" (WHO, 1992) such as emotional exhaustion, fatigue and decreased work performance (Maslach \& Schaufelli, 1993). Research has also found that burnout is associated with other negative consequences such as 'job dissatisfaction, reduced organizational commitment, intention to leave, absenteeism and staff turnover' (Maslach \& Leiter, 2008 p. 499). Maslach et al., (2001) therefore argue that the fit between the person and the workplace underpins the potential for burnout or job engagement. Therefore, if the demands of the job are in excess of an individual's capacity (perceived or otherwise), this can create a sense of misfit or incongruence with potentially negative impacts on the individual.

Why Extend the Two Process Model of Demands and Values (Leiter 2008)?

Leiter's (2008) Two Process Model distinguishes two important organizational factors that impact on workers experiencing aspects of burnout in relation to their job. These are workload demands and values. Work overload is associated with feelings of exhaustion which underpins the evidence relating to job stress and burnout research. If workers experience work overload for a prolonged period they may feel pushed beyond capacity and experience tiredness, fatigue, stress and burnout. 
As burnout is a particular risk for those who do 'people work' (Maslach \& Jackson, 1986), value congruence can be compromised if people are exhausted by the job and lack the energy to be fully engaged in the work. To further complicate the question of value congruence, one must consider individual professional values as well as the sometimes conflicting nature of corporate or employer values. When this occurs, depersonalisation can be the result and which can impact on the workers capacity for empathy, having any sense of personal accomplishment or deriving meaning from the job which can place the worker at increased risk of burnout (Laschinger \& Leiter, 2006).

Studies in other settings have similarly confirmed that resilience among school age pupils can be predicted from feelings of academic self-efficacy, control, planning/coordination, composure/anxiety and commitment to studies (Martin \& Marsh, 2006). The authors also found that resilience was subsequently predictive of enjoyment and participation at school and self-esteem. In the context of social work, this paper compares two theoretical extensions of the Two Process Model (Leiter, 2008). Firstly, we model resilience as a predictor of the feelings of control (organizational factor) and personal accomplishment (burnout factor) which could be defined as akin to self-esteem and participation in educational contexts, whist attempting to maintain the other aspects of the Two Process model. Secondly we compare this to a model where resilience acts as a mediator of the relationship between the areas of work-life subscales and burnout. In this latter model resilience may be predicted by feelings of control, as evidenced by Martin \& Marsh (2006) and by values in a social work context which is similar to the notion of commitment to studies in an educational context. This paper thus provides more theoretical information on the range of factors introduced into the model and we justify selection of additional variables to the amended and extended models using a statistical model building methodology. The models compliment theoretical understanding of burnout, job engagement and organizational factors that interact as both risk and protective factors and extend our knowledge about individual resilience and burnout in the context of organizational culture in child-protection social work or child welfare. 


\section{Organizational Culture and Climate}

Organizational culture contributes to the conditions and context for child protection social workers and the service provided. Extensive US regional and nationwide research found that children receiving a service from positive organizational social contexts had better 'clinical and functional outcomes than those who were served by negative social contexts' (Glisson \& Green, 2006, 2011, cited in Glisson et al 2012 p. 622). Efforts to improve child protection systems could benefit from greater understanding of the context in which the service is provided. Definitions of organizational culture and climate are offered by Glisson \& James (2002:767) “Climate is defined as the psychological impact of the work environment on the individual worker (e.g., emotional exhaustion, role overload) and culture is described as the organization's behavioural expectations of its employees and the way things are done in the organization (e.g., support, conformity)”.

Factors that impact on organizational climate in child protection include 'job autonomy, supportive supervisors, workload, promotional opportunities and perception of personal safety' (Stalker et al., 2007 p. 182) and organizational climate was found to be the primary predictor of positive outcomes for children (Glisson \& Hemmelgarn, 1998 p. 401). Workload (Tham \& Meagher, 2009) and supportive social relationships with managers (Chenot et al., 2009) and co-workers (Depanfillis \& Zlotnik, 2008) are cited as critical issues that contribute to retention or turnover in child protection social work staff. When high levels of burnout are found among this professional group, levels of staff turnover creates an inexperienced workforce (Anderson, 2000; Healy et al., 2009).

Maslach \& Leiter (1997) in 'The Truth about Burnout' developed a survey to measure organizational correlates to assess factors that can be understood by employee expectations versus the reality of the workplace. They argue that burnout and job engagement exist on a continuum and are expressed in peoples' relationships with their job with three interrelated dimensions of exhaustion-energy, cynicism-involvement and inefficacy-efficacy and are impacted by the workers' experience of a range of specified organizational factors (Maslach \& Leiter 2008). Job engagement, in this context, 
is expressed by levels of 'fit' between the individual and the workplace in relation to Areas of Work life relating to self-perception of workload, community support (relationships at work with coworkers and managers), perceived fairness, reward, control and values (Leiter, 2008). Therefore, it could be said that organizational correlates have the capacity to act as risk or protective factors relating to the experience of burnout or job engagement. The current paper builds on work by Leiter (2008) that relates to the Two Process Model of job engagement of the relationship between these areas of work life and burnout domains, emotional exhaustion, depersonalisation and reduced personal accomplishment (Maslach et al., 1996). An amended model and two versions of an extended model have been tested incrementally. Models have been extended to include perceptions of rewards, community and a measure of resilience using a standardised measure (Resilience Scale 14 'RS14') which includes two broad theoretical constructs of 'acceptance of self and life' and ‘individual competence' (Wagnild \& Young, 1993). The second model included resilience as a mediator variable to test this construct in the context of organizational factors, burnout and job engagement. Resilience is modelled in the final model as both an outcome of some organisational factors whilst also making a unique direct contribution to explaining burnout.

\section{Why is 'Resilience' Considered Important?}

We seek to understand whether organizational factors are predictive of resilience and if resilience mediates the relationship between organizational factors and burnout. This is important as organizational factors can be addressed by employers within a resilience building organizational culture. Resilience is also considered relevant in the current study due to the recognition that it is the experience of adversity that tests an individual's ability to recover and regain equilibrium (Masten, 2001). It needs to be acknowledged that regardless of evidence about pressures in child protection work, there are findings that suggest some child protection employees feel high levels of personal accomplishment in their role (McFadden, 2015), and that social workers can experience job satisfaction and feel they make a significant difference to people's lives (Stalker et al., 2007). 
Findings by Anderson (2000) also show that despite remuneration dissatisfaction, the majority of workers did not intend to leave. Burns (2011) also found individuals to be 'converts' to the profession despite entering thinking of the job as a 'career transient'.

\section{Organizational Correlates of Burnout}

Leiter \& Maslach (2005) summarised the organizational correlates of burnout as 'Areas of Worklife', namely workload, control, reward, community, fairness and values.

Workload: Excessive workload has been expressed as a feeling that work related demands are beyond human limits. Increased workload is strongly correlated with the exhaustion component of burnout (Maslach et al., 2001). The quantity and quality of work demands on staff can increase the pressure of the job and this diminishes levels of energy and the ability to meet workload demands. Workload is categorised as one of a range of factors that is related to excessive job demands including task interruption, work-life conflict, emotional dissonance and organizational changes (Bakker et al., 2000b).

Control: Control is defined as having the opportunity to make choices and decisions, including problem solving and contributing to the responsible actions related to one's work (Leiter \& Maslach, 2004). Congruence occurs when there is a match between control and accountability and incongruence is related to feelings of a lack of control to fulfil one's responsibilities. The dimension of 'personal control' has been identified as a significant contributor to burnout. Role conflict and role ambiguity have been associated with burnout (Cordes \& Dougherty, 1993), whereas being involved in decision making has been found to be related to positive feelings of efficacy (Cherniss, 1980, 1995; Leiter, 1992).

Reward: Reward can be financial, organizational or social reward and being recognized for one's contribution to work (Leiter \& Maslach, 2004). Inadequate reward was found to increase vulnerability to feelings of inefficacy and burnout (Chappell \& Novak, 1992). Social support such as 
receiving recognition from service users, co-workers and managers can serve as a positive social reward and this can bring feelings of pride and job satisfaction (Richardson et al., 1992).

Community: Community relates to an organization's social environment and is similar to 'reward' as it relates to the quality of social relationships such as social support from colleagues, co-workers and managers. Issues related to conflict, team cohesion and sense of 'closeness' are all important factors relating to worker susceptibility to burnout or job engagement (Maslach \& Leiter, 2008). Feelings of efficacy or personal accomplishment have been related to team support and Schaufelli et al., (2001) argues that burnout is not likely to manifest within a supportive and positive organizational context (Leiter \& Harvie, 1998).

Fairness: Fairness refers to the individual and collective evaluation by employees about justice and fairness regarding decisions at work (Leiter \& Maslach, 2004). Research on procedural justice shows that individuals are more concerned about equity in the process of decision making rather than outcomes (Tyler, 2009). Equity theory (Walster et al., 1973) informs this aspect of organizational justice. This contends that individual perceptions of fairness and justice are based on people's determination of the reciprocity exchange of what they give and what they receive. Bakker et al., (2000a) found that a sense of injustice or inequity can be a predictor of burnout. Leiter \& Harvie $(1997,1998)$ found that when a supervisor is perceived to be fair and supportive, individuals were at less risk of burnout and more adaptable to major organizational changes.

Values: Values are related to the application of meaning, using cognitive-emotional processes to set career goals and one's expectations of the job. Value conflicts therefore have the potential to affect motivation and have been found to be related to all three burnout domains (Leiter \& Harvie, 1997; Leiter \& Maslach, 2005).

Aims of the Study: This study aims to employ path analysis modelling to examine the relationships between resilience, organizational variables and burnout. We aimed to extend the Two Process 
Model (Leiter, 2008) by adding two new Aspects of Work Life subscales (Perceived Rewards and Sense of Community) and a measure of resilience to a prediction model of burnout. We assessed two competing versions of model structure. In order to best predict burnout, the modelling strategy sought to determine whether Resilience should be better modelled as a separate exogenous variable alongside additional Aspects of Work Life subscales (Perceived Rewards and Sense of Community) or as both a direct predictor and a mediator of the relationships between all Aspects of Work Life subscales and burnout. It was expected that higher Resilience would be associated with lower scores on burnout and that the two new Aspects of Work Life would be positively predictive of the original Two Process model's Aspects of Work Life subscales of Control, Fairness, Perceived Workload and Value Congruence. Demographic information was also collected relating to age, gender and length of experience (in child protection), caring responsibilities, job status, statutory or voluntary sector employment, employer and rural urban service area. The inclusion of demographics was beyond the scope of the current analysis but are reported elsewhere (McFadden, 2013).

Methodology: This study used a cross-sectional online survey questionnaire design that included the Maslach Burnout Inventory, MBI (Maslach \& Leiter, 1986), the Resilience Scale-14, RS-14 (Wagnild \& Young, 1993) and the Area of Work Life Scale, AWLS, (Leiter, 2008). The survey was distributed using Smart Survey software (C) and was delivered by email to social workers who had confidential status to maximise participation.

Sampling Frame: The sampling technique used in the study combined cluster sampling and stratified random sampling. It was appropriate to use cluster sampling as the social workers under study formed natural groups. The sampling techniques were applied across six participating organizations. Five Health and Social Care Trusts and those employed within a voluntary sector organization The population of social workers contained natural groupings into a number of strata (Gateway -first point of referral), Family Intervention / Support (longer term service), voluntary sector therapeutic support. The strata were further differentiated by demographic variables such as social worker age, 
gender, length of experience, job status, employer, caring responsibilities, post qualifications, qualifications and rural/urban service area. This method of sampling increases the ability to claim representativeness but the authors use this claim cautiously due to the sample size drawn from each strata (see Table 1 below). The sample included those in their Assessed (first) Year in Employment (AYE), front line social work posts, those in senior practitioner posts and team leaders. The emphasis was on those who held caseloads and professional accountability for risk and protection of vulnerable children and families. The overall population of social workers who met the inclusion criteria was 380 and the survey achieved a response rate of 162. Statistical power for path models depends on model complexity and other factors such normality of the data and missing data patterns. Most researchers would recommend using sample sizes of at least 200 or a minimum of 5 cases per parameter estimated (Kline, 2011, pp: 11-12). The Shapiro-Wilk tests showed that all of the modelled variables were approximately normally distributed and the final path model estimated a total of 32 parameters thus rendering the ratio of cases to parameters estimated at 5.06.

\section{Insert Table 1 here}

Sample Characteristics: A total of 140 females (86\%) and 22 males (14\%) responded to the survey. This ratio was consistent with the gender profile of social workers in Northern Ireland and is consistent with the gender ratio of social work more widely (NISCC, 2014 p. 20). The contract status levels were reflected across the sample ranging from those in their first assessed year of employment (AYE) through to senior practitioner and those "acting" in team leader posts. The largest groups of participants were social workers who had permanent contracts at $67 \%(n=109)$, followed by senior practitioners $9 \%(n=14)$, those in their assessed year in employment $8 \%(n=13)$ and Agency (sessional) staff $6 \%(n=10)$, temporary social workers $(n=10)$ and acting team leaders $(n=6)$. Family Intervention Social workers made up $56 \%$ of the sample $(n=91)$ and Gateway (initial referral teams) $33 \%(n=53)$. Although the response rate from the Voluntary Sector is high, the actual percentage of participants in the overall sample was $11 \%$ with $5 \%$ categorised as "child protection" and $6 \%$ as 
"therapeutic" social work staff. Those with less than two years' experience represented $11 \%(\mathrm{n}=$ 46) and those with less than three years' experience made up $43 \%(n=69)$ of the sample. Those with five or more years of experience made up $34 \%(n=55)$ of the sample.

Ethical Approval: The study was approved by the Office of Research Ethics in Northern Ireland (3 August, 2010 Application No 10/NIR03/23). Ethical and Governance Approval was also granted by Ulster University and the Research and Development Offices of all five Health \& Social Care (HSC) Trusts, as well as a voluntary sector child protection agency. The main ethical issue related to the need for a protocol to manage any identification of poor or concerning practice associated with burnout and a protocol was agreed to manage this potential. Social work is a regulated profession and all participants work within an ethical code of conduct as set by the Northern Ireland Social Care Council which was an added safeguard for practice governance. All participants gave informed consent to participate in the study and participation was voluntary and strictly confidential.

Measures: All measures used were standardised psychometric scales. The Resilience Scale RS-14 (Wagnild \& Young, 1993) has 14 items measuring resilience across five broad areas of self-reliance (5 items), meaning (3 items), equanimity ( 2 items), perseverance (2 items) and existential aloneness (2 items). The RS-14 utilizes a Likert-type response format ranging from 1 (strongly disagree) to 7 (strongly agree). Self-reliance is having confidence and belief about one's life-role and the ability to accept strengths and limitations in oneself. Meaningfulness is being able to understand life's purpose and meaning, providing a reason for living. Equanimity is a balanced view of life experiences as well as an ability to take a perspective and an overview of a broader range of experiences and be prepared for unforeseen challenges. Perseverance is the act of being persistent despite experienced adversity or a lack of encouragement. It also is characterised by self-discipline, an ability to redefine oneself and having a grounded determination to remain actively involved in how adversities are managed. Existential aloneness is about understanding ones' aloneness in the world and the uniqueness of ones' life and experiences and individual responsibilities (Wagnild, 
2009a p. 23). Resilience items measure statements such as 'I usually manage one way or another', (self-reliance), 'My life has meaning' (meaning), 'I usually take things in my stride' (equanimity), 'self-discipline is important' (perseverance) and 'My belief in myself gets me through hard times' (existential aloneness). The authors thus intended the RS-14 to be used as a single core construct, wherein being resilient is a combination of protective factors working together to produce positive outcomes to stressors (Wagnild, 2009a, 2009b; Wagnild \& Young, 1993). For this reason, scores on all 14 items were combined into a single summated resilience score with higher scores indicating higher levels of expressed resilience. Internal consistency was assessed using Cronbach's alpha $(a=90$.

The Maslach Burnout Inventory (Maslach \& Jackson, 1986) has well documented psychometric properties designed to measure a respondent's self-perception of emotional exhaustion, depersonalisation and personal accomplishment. A series of twenty two questions measure these three domains and participants report frequency of experienced feelings and thoughts using a Likert scale ranging from 0 'Never' to 6 'Every Day' and measures the individual's experience of job burnout. The exhaustion component (9 Items) is linked to the psychological strain associated with individual experience of burnout. Depersonalisation (5 Items) is the interpersonal context and measures emotional detachment or negative feelings towards service users and other aspects of the job. The Personal Accomplishment dimension (8 Items) is related to the self-evaluation dimension of burnout and is experienced when an individual has feelings of incompetence or a lack of achievement in relation to their job. Internal consistencies for each of the sub-scales were all acceptable, Emotional Exhaustion $(\alpha=.90)$, Depersonalisation $(\alpha=.75)$ and Personal Accomplishment $(\alpha=.78)$.

The Area of Work life Scale AWLS has 29 items and measures organizational factors of Workload, Community, Control, Fairness, Reward and Values (Leiter \& Maslach, 2008). The items are worded in terms of perceived congruence (fit) or incongruence (misfit) between self and workplace. Items 
reflect positively framed statements of congruence, for example, "I have enough time to do what's important in my job", as well as negatively framed items of incongruence such as, "Working here forces me to compromise my values". Agreement or disagreement of these statements is ranked using a five point Likert scale, from 1 "strongly disagree" to 5 "strongly agree" (Maslach \& Leiter, 2008) and scoring for the negatively framed items is reversed. This tool defines congruence as a high score (greater than 3.00) which indicates a high degree of "fit" between self and work place. The reverse is true for incongruence. In this instance the score is low (less than 3.00) which suggests a "misfit" between the person and workplace. Maslach \& Leiter (2008), found that job-person incongruity is directly related to burnout. In earlier work, these authors (Maslach \& Leiter, 1997) developed a model of burnout that gave specific attention to the perceived fit or congruency between the employee and specific aspects of their organizational working context. The model found that the greater degree of misfit is directly related to a high potential for burnout. By the same token, higher levels of job-person congruity were found to be associated with higher degrees of job engagement. Internal consistency coefficients for the AWLS were all above .7 with the exception of Control $(\alpha=$ $.68)$. All other scales performed as follows: Values $(\alpha=.74)$, Fairness $(\alpha=.77)$, Reward $(\alpha=.84)$, Community $(\alpha=.87)$, Workload $(\alpha=.91)$.

\section{Path Analysis Strategy}

Path analysis based on maximum likelihood estimation was used to estimate a series of mediated models of the relationships among the observed variables using Leiter's (2008) Two Process model of burnout and work engagement as the starting point (Figure 1). Model fit was assessed using a number of indices.

1. The $\chi^{2}$ Goodness-of-fit test based predicted and observed covariance with lower values indicating better fit.

2. Root Mean Square Error of Approximation (RMSEA) (Steiger, 1990). RMSEA ranges from 0-1 with lower values indicative of better model fit. Steiger (2007) suggests an upper limit of 
0.07. Confidence intervals were also calculated (MacCallum et al., 1996) which allows for poor fit to be tested more precisely (McQuitty, 2004). In a well-fitting model, a lower confidence interval close to 0 and an upper limit less than 0.08 is considered optimal (Hooper et al., 2008).

3. Standardized Root Mean Residual (SRMR). Values for the SRMR range from zero to 1.0 with values less than .05 indicative of good fitting models (Byrne, 1998; Diamantopoulos \& Siguaw, 2000), and values up to 0.08 are deemed acceptable (Hu \& Bentler, 1999).

4. Comparative Fit Index (CFI; Bentler 1990). The CFI values range 0-1 with a value of .90 or larger is considered to indicate acceptable model fit. (Hu \& Bentler, 1999)

5. The Non Normed Fit Index (Tucker \& Lewis, 1973). Values typically range from 0 to 1 but values over 1 are possible making it more difficult to interpret (Byrne, 1998). Minimum recommendations for the NNFI range from 0.80 with values $\geq .95$ being preferred (Hu \& Bentler, 1999).

Results

Descriptive statistics, Pearson correlations and Cronbach's alpha coefficients were obtained using SPSS Version 22 (SPSS, 2014) and the path models were estimated in MPLUS 7 (Muthén \& Muthén, 1998-2014). Table 2 illustrates the zero-order Pearson correlations among Resilience, MBI and AWLS subscales and presents descriptive statistics and reliability coefficients for each.

Resilience correlations with Burnout and AWLS: Table 2 demonstrates moderate to strong correlations between the Resilience and both Depersonalisation (DP) $\mathrm{r}(162)=.38, p<.01$ and Personal Accomplishment (PA) $\mathrm{r}(160)=.52, p<.01$. Resilience was also moderately associated with some of the AWLS factors, namely perceptions of having a manageable Workload $\mathrm{r}(162)=.21, p$ $<.01$, Control $\mathrm{r}(162)=.22, p<.01$ and Value Congruence $(\mathrm{VC}) \mathrm{r}(162)=.22, p<.01$. 
AWLS correlations with Burnout: As expected perceptions of having a Manageable Workload was negatively associated Emotional Exhaustion (EE) $\mathrm{r}(162)=-.62, p<.01$, Depersonalisation (DP) $\mathrm{r}(162)=-.26, p<.01$ and positively linked to Personal Accomplishment (PA) $\mathrm{r}(162)=.35, p<.01$. A similar pattern of correlations was observed between Control, Rewards, Fairness and Values and all three burnout measures with the strongest correlations between Control and $\operatorname{EE} \mathrm{r}(162)=-.39, p$ $<.01$, Reward and EE $\mathrm{r}(162)=-.35, p<.01$ and Values and $\operatorname{EE} \mathrm{r}(162)=-.37, p<.01$. Positive correlations in the range .20 to .35 were also observed between five of the six AWLS subscales and PA (with the exception of Community). Sense of Community scores was not significantly associated with any of the burnout subscales $(p>.05)$.

\section{Insert Table 2 Here Correlation Matrix}

\section{Amended Two Process Model}

The Two-Process model was initially tested with poor model fit observed $\chi^{2}(12)=35.59, p=.002$, $\mathrm{RMSEA}=.10,90 \% \mathrm{CI}$ RMSEA $=.58-.14$. Adequate fit was achieved with the addition of a direct path estimate from Workload to Personal Accomplishment $\chi^{2}(11)=18.99, p>.05$, RMSEA $=.07$, $90 \%$ CI RMSEA $=.00-.12$ (Table 3). It was also noted that the path from Values to DP was not statistically significant $(p>.05)$ and so a re-estimated model with this path removed for parsimony resulted in improved model fit $\chi^{2}(12)=19.99, p>.05$, RMSEA $=.06,90 \%$ CI RMSEA $=.00-.11$ All estimated path coefficients shown in Figure 1 were statistically significant $(p<.05)$. The largest standardised coefficients were evident in the paths from perceptions of a Manageable Workload to $\mathrm{EE}(\beta=-.58, p<.005)$, which in turn directly predicted $\mathrm{DP}(\beta=.37, p<.01)$. A weaker standardised path from DP to PA was also recorded $(\beta=-.14, p<.05)$. The model showed that having a Manageable Workload both directly predicted PA $(\beta=.28, p<.01)$ and indirectly via EE and DP. Values also predicted EE directly $(\beta=-.18, p<.05)$, DP indirectly via EE and PA indirectly via EE and DP. 


\section{Extending the Two Process model}

Having established adequate model fit for an amended Two Process model, new constructs were added to the model, namely Reward, Community and Resilience. The analysis strategy involved extending the two-process model by comparing two structurally different models. The first modelled Reward, Community and Resilience as additional exogenous variables on Control, Fairness, Workload and Value Congruence which in turn predicted Burnout in line with the Two Process model (Figure 2A). The second model also used Reward and Community as exogenous variables in the same way as model 1 but Resilience was specified as a mediator of the relationships between Aspects of Work subscales (plus Reward and Community) and the burnout subscales (Figure 2B).

\section{Extended model 1 (Figure 2A)}

Resilience was added as a direct predictor of both Control and Community and specified as a direct predictor of Fairness. Sources of strain in the model were identified using modification indices (MIs) and the model was incrementally re-specified using single modifications. Each stage of the model fitting process resulted in the addition of direct paths from Resilience to $\mathrm{PA}(\mathrm{MI}=36.3, \beta=-.58, p<$ $.005)$, Rewards to Control $(\mathrm{MI}=29.4, \beta=.42, p<.005)$, Rewards to Values $(\mathrm{MI}=14.3, \beta=.32, p<$ $.01)$, Resilience to $\mathrm{EE}(\mathrm{MI}=12.2, \beta=-.23, \mathrm{p}<.01)$ and Workload to Reward $(\mathrm{MI}=10.37, \beta=.26, p<$ $.01)$. This model fitted the data well $\chi^{2}(26)=37.95, p>.05$, RMSEA $=.05,90 \%$ CI RMSEA $=.00-$ .09 with statistical significance $(p<.01)$ achieved on all estimated paths with the exception of the path from Value Congruence to Depersonalisation $(p>.05)$. Removal of this path did not significantly degrade the model fit $\chi^{2}(27)=38.95, p>.05$, RMSEA $=.05,90 \%$ CI RMSEA $=.00$ .10 (Figure 2a). To summarise the key paths in this model it was found that Resilience directly predicted two aspects of burnout, namely $\mathrm{EE}(\beta=-.23, p<.05)$ and $\mathrm{PA}(\beta=.46, p<.005)$ and indirectly predicted these same two aspects of burnout via perceptions of Control and having a Manageable Workload. The relationship between Resilience and DP was completely indirectly 
mediated via EE and via Control, Workload and EE. Reward perceptions also directly predicted feelings of Control $(\beta=.42, p<.01)$ and having a Manageable Workload $(\beta=.26, p<.05)$, as well as perceptions of Fairness $(\beta=.40, p<.01)$ and Value Congruence $(\beta=.32, p<.01)$. Consistent with the original Two-Process Energy and Values model (Leiter, 2008), the relationship between perceived Rewards and Burnout was fully mediated via perceptions of Control, Fairness, Value Congruence and having a manageable Workload. This extended model 1 accounted for $45 \%, 14 \%$ and $33 \%$ of the variance in the subscale scores of Emotional Exhaustion, Depersonalisation and Personal Accomplishment respectively (Table 4). INSERT FIGURES 2A and 2B here

Extended model 2 (Figure 2B)

Reward was specified as directly predicting Control, Fairness, Workload and Value Congruence and Community was specified as directly predictive of Fairness. Resilience was specified as both a direct outcome of Control, Workload, Value Congruence and Fairness and directly predictive of the three Burnout subscales (EE, DP and PA). Best model fit was achieved using the same incremental modification strategy employed in previous models. The initially specified model did not fit the data $\chi^{2}(24)=45.92, p=.045, \mathrm{RMSEA}=.08,90 \%$ CI RMSEA $=.04-.11$ with five non-significant paths $(p>.05)$, namely, Workload and Fairness to Resilience, Control to Fairness, Values to Personal Accomplishment, Resilience to Depersonalisation. Removing these paths did not significantly degrade the model fit $\chi^{2}(29)=50.57, p=.007$, RMSEA $=.07,90 \%$ CI RMSEA $=.04-.10$ and including an additional path from Reward to Values $(\mathrm{MI}=14.29, \beta=.32, p<.01)$ significantly improved overall model fit $\chi^{2}(28)=35.61, p=.15$, RMSEA $=.04,90 \%$ CI RMSEA $=.00-.08$. (See figure 2a). All paths in extended model 2 were statistically significant $(p<.05)$ and the model accounted for the same amount of variance in each of the three Burnout subscales as extended model 1 (namely, 45\%, 14\% and 33\% of EE, DP and PA respectively). In addition, extended model 2 also accounted for $7 \%$ of the variance in Resilience scores (Table 4). 
As in extended model 1, having a manageable Workload remained the strongest direct predictor of $\mathrm{EE}(\beta=-.54, p<.005)$ and Resilience produced the same direct relationships with $\mathrm{EE}(\beta=-.23$, $p<.005)$ and PA $(\beta=.46, p<.005)$. Only two organisational factors (Feelings of Control and Value Congruence) were directly weakly predictive of Resilience $(\beta=.18, p<.05$ and $\beta=.17, p<.05$ respectively) but Resilience was also indirectly predicted by other workplace factors of Reward, Community and Fairness. Adding Reward to extend the Two Process Model produced moderate direct positive associations with Control $(\beta=.44, p<.005)$, Workload $(\beta=.26, p<.005)$, Fairness $(\beta$ $=.40, p<.005)$ and Values $(\beta=.32, p<.005)$, whereas the addition of Community only produced one direct path to Fairness $(\beta=.28, p<.005)$. Insert Table 3 followed with Table 4 Here

In summary, the two extended Models both work well in accounting for variability in Emotional Exhaustion scores $\left(\mathrm{R}^{2}=.45\right)$, Depersonalisation $\left(\mathrm{R}^{2}=.14\right)$ and Personal Accomplishment $\left(\mathrm{R}^{2}=.33\right)$. The final model accounts for more variability in Control $\left(\mathrm{R}^{2}=.22\right)$ and Resilience $\left(\mathrm{R}^{2}=.07\right)$.

\section{Discussion}

Resilience directly predicts two aspects of burnout, namely Emotional Exhaustion and Personal Accomplishment. A direct relationship between Emotional Exhaustion and Depersonalisation was evident in each model in the analysis. This is consistent with recent research by Lizano \& Mor Barak (2015) who found that regardless of social support and specialized training, Emotional Exhaustion was positively related to Depersonalization and negatively related to job satisfaction in a sample of child welfare employees. Findings from a recent UK wide study of social worker burnout (McFadden, 2015) found the co-existence of Emotional Exhaustion and personal accomplishment in more than half of a sample of 1359 social workers. The coexistence of Exhaustion and Accomplishment is likely to result in levels of internal conflict or increased stress. Workload can also be linked directly to Emotional Exhaustion and Personal Accomplishment, so when workload is perceived as incongruent between jobs demands and human capacity, individuals feel high levels of Emotional Exhaustion which increases their risk of burnout. Our findings contribute to the existing 
research literature by exploring individual resilience levels in the context of the organizational factors that impact on levels of burnout. So we can say that organizational factors such as Control, Workload, Fairness and Values, Reward and Community impact on participant job burnout in a range of complex pathways.

The analysis confirmed resilience as making a distinct contribution to the Two-Process Model of burnout by explaining additional variance in exhaustion beyond that explained by manageable Workload and Values. Second, Resilience contributed to explaining additional variance in Personal Accomplishment beyond that explained by the Two-Process Model. When Resilience was added to the model it replaced the path from Values to Personal Accomplishment, suggesting that Resilience contributes to social workers' self-evaluation. The analysis confirms the distinct relationship of manageable Workload with Exhaustion and the broader connection of Values with both Exhaustion and Personal Accomplishment, although the previously confirmed connection with

Depersonalization was absent in this analysis. This distinction may arise from the version of the MBI used: the previous analyses used the cynicism subscale of the MBI General Scale; this analysis used the Depersonalization subscale of the Human Services Scale. Although Depersonalization was significantly correlated with Values, Values was more strongly correlated with Exhaustion which in turn was highly correlated with Cynicism. This pattern suggests that the hypothesized model's direct path from values to Depersonalization is replaced by an indirect relationship of values to Depersonalization that is partially mediated through Exhaustion.

Further, it has been demonstrated that Depersonalization in the MBI-HSS and Cynicism in the MBI-GS have distinct structural characteristics. Specifically, Salanova et al (2005) found a better fit for a four-factor model with separate Depersonalization and Cynicism subscales than for a threefactor model that combined their items into a single factor. The difference between the two constructs is evident in their pattern of correlations. In this analysis, Exhaustion was more strongly correlated than was Depersonalization for every area of worklife. In contrast, analyses with the 
Cynicism subscale of the MBI-GS report stronger correlations for Cynicism than for exhaustion for all areas of worklife except for workload (e. g., Leiter, Day, \& Price, 2015). From a theoretical perspective, Salanova et al (2005) argued that the focus on social relationships in the Depersonalization scale introduces a distinct dimension of the work experience, especially for people working in human services. That is, becoming cynical about the administrative burdens of work reflects a different sort of alienation than losing the personal qualities of therapeutic relationships with service recipients.

Another striking distinction is the absence of any correlations of the MBI subscales with Community. Although the level and range of scores on Community were similar to those in other samples, the quality of community was unrelated to burnout. The absence of connections with Community — in the context of connections with the other five areas of worklife - raises the possibility that social workers, despite the name of their profession-may not engage deeply in the social context of their work. Depersonalization is the withdrawal of emotional connection from social encounters, suggesting that the weaker correlations with Depersonalization may reflect lesser importance for collegial relationships, a particular risk when workers experience higher levels of exhaustion. Reward refers to social reward as well as remuneration and the relationship between Reward and Values may explain why Community was not found to be directly related to burnout. Instead the relationship of Community with aspects of burnout was mediated through Reward and Fairness. Is it the case that social workers perceive the role of Reward as more supportive than that of Community without Reward? These are questions for further research and these findings uncover something interesting about this differentiation. This model reflects that an objective of interventions to improve workplace health and wellbeing is to increase employee resilience. Ideally, the management environment as reflected in the areas of worklife contribute to employees' resilience, reducing their vulnerability to burnout.

\section{Limitations of the Study}


The main limitation of the study is the self-reported nature of the survey and the potential motivation to participate being disproportionally drawn from 'unhappy' employees. This has the potential of skewing the data however, the balance of findings reflects both positive and negative experiences therefore it does not appear that the issue of negative skewedness has been found. The response rate was $43 \%$ could also be considered a limitation, however, due to the level of work-pressure for social workers, including time capacity regarding workload, this response rate was considered an achievement. The response rate was considered acceptable to provide insight into the working conditions of those who participated in the study as a statistician calculation had identified that 125 responses would provide statistically significant results to the power of 0.80 (Shevlin, 2010, see Appendix F). As the sample was a random selection, the results from the quantitative part of the study are representative and generalizable across child protection social work staff in Northern Ireland. A limitation of the analysis might be that the model has not accounted for demographic variables. Due to the complexity of this method and statistical power considerations given the number of variables, it was not efficient to include such additional variables. The data had also been subjected to regression analysis in a separate publication (McFadden, 2013) where only significant results relating to demographic findings are reported. Furthermore, similar to the Leiter (2008) study, this paper is limited by not having the ability to report longitudinal data. Response bias was managed by reporting only on statistically significant results and those with low correlations were omitted from the final model.

\section{Conclusion}

This paper has considered the relationship between Resilience and Areas of Work Life that are related to burnout in child protection social workers. The overall analysis shows that some measured organisational factors predict a little of the variance in Resilience scores (but only 7\%). Also, the last model did not seek to explain Resilience in this way as it treated Resilience as an exogenous variable in the extended Two Process model. In the new model, Resilience is modelled as an both an outcome of some organisational factors and whilst also making some unique direct contribution to explaining 
burnout alongside other organisational factors as specified within an extended version the Two Process Model.

Future direction for research in this area is to employ longitudinal methods so that causal inferences may be made as a result of measuring results with the same sample over time. Nonetheless, our findings are important and highlight levels of Emotional Exhaustion and Depersonalisation that are concerning for this occupational group. It is suggested that organizations should carefully consider factors that promote Resilience in the child protection work force to counter the likelihood of burnout in this critical area of social work practice with the consequential impact on individual staff resilience and the workforce resilience more widely.

\section{References}

Aiena, B. J., Baczwaski, B. J., Schulenberg, S. E., \& Buchanan, E. M. (2015). Measuring resilience with the RS-14: A tale of two samples. Journal of Personality Assessment, 97(3), 291-300. Anderson, D. G. (2000). Coping strategies and burnout among veteran child protection workers. Child Abuse \& Neglect, 24(6), DOI: 839-848. PII S0145-2134(00)00143-5

Bakker, A. B., Schaufeli, W. B., Demerouti, E., Janssen, P. M. P., Van der Hulst, R., \& Brouwer, J. (2000a). Using equity theory to examine the difference between burnout and depression. Anxiety, Stress, \& Coping, 13, 247-268. DOI: 10.1080/10615800008549265

Bakker, A., Schaufeli, W., Sixma, H., Bosveld, W., \& Van Dierendonck, D. (2000b). Patient demands, lack of reciprocity, and burnout: A five-year longitudinal study among general practitioners. Journal of Organizational Behavior, 21(4), 425-441. doi: 10.1002/(SICI)10991379(200006)21:4<425::AID-JOB21>3.0.CO;2-\#

Bentler, P. M. (1990). Comparative fit indexes in structural models. Psychological Bulletin, 107(2), 238-46. DOI: $10.1037 / / 0033-2909.107 .2 .238$ 
Brandon, M., Bailey, S., \& Belderson, P. (2010). Building on the Learning from Serious Case Reviews: A two-year analysis of child protection database notifications 2007-2009. London:

Department for Education. Available at:

https://www.gov.uk/government/uploads/system/uploads/attachment data/file/181651/DFE-

\section{$\underline{\text { RR040.pdf }}$}

Brandon, M., Bailey, S., Belderson, P., Gardner, R., Sidebotham, P., Dodsworth, J., et al. (2009).

Understanding Serious Case Reviews and their Impact: A Biennial Analysis of Serious Case Reviews 2005-07. London: Department for Children, Schools and Families. Available at:

$\underline{\text { http://dera.ioe.ac.uk/11151/1/DCSF-RR129(R).pdf }}$

Burns, K. (2011). Career preference, transients and converts: A study of social workers' retention in child protection and welfare. British Journal of Social Work, 41(3), pp. 520-538.

DOI:10.1093/bjsw/bcq135

Byrne, B.M. (1998), Structural Equation Modelling with LISREL, PRELIS and SIMPLIS: Basic Concepts, Applications and Programming. Mahwah, New Jersey: Lawrence Erlbaum Associates. ISBN 9781138012493

Chappell, N., \& Novak, M. (1992). The role of support in alleviating stress among nursing assistants. Gerontologist, 32(3), 351-359. DOI: 10.1093/geront/32.3.351

Chenot, D., Benton, A. D., \& Kim, H. (2009). The influence of supervisor support, peer support, and organizational culture among early career social workers in child welfare services. Child Welfare, 88(5), 129-148. DOI: 0009-4021/2009/0509129-147 CWLA

Cherniss, C. (1980). Staff burnout: Job stress in the human services. Beverly Hills; London: Sage. ISBN-10: 0803913389 / ISBN-13: 978-0803913387

Cherniss, C. (1995). Beyond Burnout: Helping teachers, nurses, therapists, and lawyers recover from stress and disillusionment. New York; London: Routledge. ISBN-13: 978-0415912051 / ISBN10: 0415912059 
Cordes, C., \& Doherty, T. (1993). A review and an integration of research on job burnout. Academy of Management Review, 18(4), 621-656. DOI:10.5465/AMR.1993.9402210153

Depanfilis, D., \& Zlotnik, J. L. (2008). Retention of front-line staff in child welfare: A systematic review of research. Children and Youth Services Review, 30(9), 995-1008.

DOI:10.1016/j.childyouth.2007.12.017

Diamantopoulos, A. and Siguaw, J.A. (2000), Introducing LISREL. London: Sage Publications. ISBN 0761951709 / ISBN 0761951717

Ellett, A. J. (2009). Intentions to remain employed in child welfare: The role of human caring, selfefficacy beliefs, and professional organizational culture. Children and Youth Services Review, 31(1), 78-88. http://dx.doi.org/10.1016/j.childyouth.2008.07.002

Faul, F., Erdfelder, E., Lang, A-G., and Buchner, A. (2007). 'A flexibile statistical power analysis program for the social and behavioral sciences'. Behavior Research methods, 39, pp 175-191

Fernandes, G. (2016). Organizational climate and child welfare workers' degree of intent to leave the job: Evidence from New York. Children and Youth Services Review January 60:80-87. DOI:

\subsection{6/j.childyouth.2015.11.010}

Glisson, C., \& Hemmelgarn, A. L. (1998). The effects of organizational climate and interorganizational coordination on the quality and outcomes of children's service systems. Child Abuse \& Neglect, (22)401-421. PII S0145-2134(98)00005-

Glisson, C., \& James, L. R. (2002). The cross-level effects of culture and climate in human service teams. Journal of Organizational Behavior, 23, 767-794.

Glisson, C. Green, P \& William, N. (2012). Assessing the Organizational Social Context (OSC) of child welfare systems: Implications for research and practice. Children's Mental Health Services Research Center, University of Tennessee, Knoxville, TN, USA. Child Abuse \& Neglect 36(2012) 621-632. DOI:10.1016/j.chiabu.2005.12.010 
Healy, K., Meagher, G., \& Cullin, J. (2009). Retaining novices to become expert child protection practitioners: Creating career pathways in direct practice. British Journal of Social Work, 39(2), 299317. DOI:10.1093/bjsw/bcm125

Hu, L., \& Bentler, P. M. (1999). Cut off criteria for fit indexes in covariance structure analysis: Conventional criteria versus new alternatives. Structural Equation Modelling, 6(1), 1-55. DOI: $10.1080 / 10705519909540118$ Hooper, D., Coughlan, J. and Mullen, M.R., (2008). Structural Equation Modelling: Guidelines for Determining Model Fit. Electronic Journal of Business Research Methods, 6 (1), 53-60. ISSN 14777029. Available online at www.ejbrm.com

Kline, Rex B. (2011), Principles and Practice of Structural Equation Modelling. New York: Guilford Press.

Laschinger, H. K. S., \& Leiter, M. P. (2006). The impact of nursing work environments on patient safety outcomes: The mediating role of burnout/engagement. Journal of Nursing Administration, 5, $259-267$.

Leiter, M. P. (2008). A Two Process Model of Burnout and Work Engagement: Distinct Implications of Demands and Values. Giornale Italiano di Medicina del Lavoro ed Ergonomia Supplemento A, Psicologia, 30(1), A52-A58. ISSN 0391-9889

Leiter, M. P. (1992). Burnout as a crisis in professional role structures: Measurement and conceptual issues. Anxiety, Stress, \& Coping, 5, 79-93. DOI: 10.1080/10615809208250489

Leiter, M. P., Day, A., \& Price, L. (2015). Attachment styles at work: Measurement, collegial relationships, and burnout. Burnout Research, 2, 25-35.

Leiter, M, and Harvie, P, (1998). Conditions for staff acceptance of organizational change: Burnout as a mediating construct. Anxiety, Stress and Coping, 11, 1-25. DOI: 10.1080/10615809808249311 
Leiter, M. P., \& Harvie, P. (1997). The correspondence of supervisor and subordinate perspectives on major organizational change. Journal of Occupational Health Psychology, 2, 1-10.

DOI: $10.1037 / 1076-8998.2 .4 .343$

Leiter, M. P., \& Maslach, C. (2004). Areas of worklife: A structured approach to organizational predictors of job burnout. In P. Perrewe' \& D. C. Ganster (Eds.), Research in occupational stress and well-being (Vol. 3, pp. 91-134). Oxford, United Kingdom: Elsevier. DOI: 10.1016/S1479$3555(03) 03003-8$

Leiter, M. P., \& Maslach, C. (2005). A mediation model of job burnout. In A. S. G. Antoniou \& C.

L. Cooper (Eds.), Research companion to organizational health psychology (pp. 544-564).

Cheltenham, United Kingdom: Edward Elgar. Available at:

https://www.researchgate.net/publication/232511448_A_mediation_model_of_job_burnout

Martin, A. J., \& Marsh, H. W. (2006). Academic resilience and its psychological and educational correlates: A construct validity approach. Psychology in the Schools, 43(3), 267-281.

Maslach, C, and Jackson, S, (1986). Maslach Burnout Inventory Manual (2 ${ }^{\text {nd }}$ Ed.). CA: CPP, Inc. CA. Open Library OL2233887M. LC Control Number 8910257

Maslach, C, Jackson, S, Leiter, M, (1996). Maslach Burnout Inventory Manual (3 ${ }^{\text {rd }}$ Ed) CPP, Inc. CA

Maslach, C., \& Leiter, M. P. (1997). The Truth about Burnout. San Francisco: Jossey Bass.

Maslach, C., Jackson, S. E., \& Leiter, M. P. (1996). Maslach Burnout Inventory manual (3rd ed.). Palo Alto, CA: Consulting Psychologists Press.

Maslach, C. and Leiter, M. (2008). Early Predictors of Job Burnout and Engagement, Journal of Applied Psychology, 9(3), 498-512. DOI: 10.1037/0021-9010.93.3.498

Maslach, C., Schaufeli, W. B., \& Leiter, M. P. (2001). Job burnout. In S. T. Fiske, D. L. Schacter, \& C. Zahn-Waxler (Eds.). Annual Review of Psychology, 52, 397-422. DOI: 10.12691/ajap-1-1- 
Maslach, C., \& Leiter, M. P. (2005). Stress and burnout: The critical research. In C. L. Cooper (Ed.). Handbook of stress medicine and health (2nd ed., pp. 153-170). London: CRC Press

Maslach, C., \& Schaufeli, W. B. (1993). Historical and conceptual development of burnout. In W. B. Schaufeli, C. Maslach, \& T. Marek (Eds.), Professional burnout: Recent developments in theory and research (pp.1-16). Washington, DC: Taylor \& Francis.

Masten, A. S. (2001). Ordinary Magic: Resilience processes in development. American Psychologist, $56,227-238$.

MacCallum, R. C., Browne, M. W., \& Sugawara, H. M. (1996). Power analysis and determination of sample size for covariance structure modelling. Psychological Methods, 1, 130-149. DOI: 10.108298

McFadden, P., Campbell, A., \& Taylor, B. (2014) 'Resilience and Burnout in Child Protection Social Work: Individual and Organizational Themes from a Systematic Literature Review'. British Journal of Social Work (2014) 1-18. doi:10.1093/bjsw/bct210

McFadden, P. (2015). Measuring Burnout among UK Social Workers: A Community Care Study. Available at https://s3-eu-west-1.amazonaws.com/rbicommunities/wpcontent/uploads/sites/7/2015/07/Burnout-among-UK-social-workers.pdf McFadden, P. (2013) Resilience and Burnout In Child Protection Social Work, PhD Thesis, University of Ulster, Northern Ireland. Retrieved from http://ethos.bl.uk 9X/96/\$3.1XI82 1082

McGowan, B. G., Auerbach, C., \& Strolin-Goltzman, J. S. (2009). Turnover in the child welfare workforce: A different perspective. Journal of Social Service Research, 35(3), 228-235. DOI: $10.1080 / 01488370902900782$.

McQuitty, S. (2004). Statistical power and structural equation models in business research. Journal of Business Research, 57 (2), 175-83. DOI: 10.1016/S0148-2963(01)00301-0 
Munro, E. (2011). The Munro Review of Child Protection: A Child Centred System. Department for Education, UK (May 2011). Available at:

https://www.gov.uk/government/uploads/system/uploads/attachment data/file/175391/Munro-

\section{$\underline{\text { Review.pdf }}$}

Muthén, L.K. and Muthén, B.O. (1998-2015). Mplus User’s Guide. Seventh Edition. Los Angeles, CA: Muthén \& Muthén. Available at:

http://www.statmodel.com/download/usersguide/Mplus\%20Users\%20Guide\%20v6.pdf

NISCC (2014) Five Year Periodic Review of the Degree in Social Work. Northern Ireland Social Care Council. Available at:

http://www.niscc.info/files/Publications/20130809 ReviewOfDegreeReport 2013-

\section{FV MOR.pdf}

Parton, N. (2012). The Munro Review of Child Protection: An Appraisal. Children \& Society, 26(12) pp 150-162. DOI:10.1111/j.1099-0860.2011.00415.x

Parton, N. (2014). The Politics of Child Protection: Contemporary Developments and Future Directions, Basingstoke: Palgrave Macmillan, 2014. pp 258. DOI: 10.1111/j.10990860.2011.00415.x

Pick, D., \& Leiter, M. P. (1991). Nurses' perceptions of the nature and causes of burnout: A comparison of self-reports and standardized measures. The Canadian Journal of Nursing Research, 23(3), 33-48.

Richardson, A, Burke, R, and Leiter, M. (1992). Occupational demands, psychological burnout and anxiety among hospital personnel in Norway. Anxiety, Stress and Coping, (5) pp 62-78. DOI: $10.1080 / 10615809208250487$

Salanova, M., Llorens, S., García-Renedo, M., Burriel, R., BresÓ, E., \& Schaufeli, W. B. (2005). Towards a four-dimensional model of burnout: A multigroup factor-analytic study including depersonalization and cynicism. Educational and Psychological Measurement, 65, 807-819 
Schaufelli W, Bakker A, Hoogduin, K, Schaap, C, and Ladle, A. (2001). On the Clinical Validity of the Maslach Burnout Inventory and the Burnout Measure, Journal of Psychology and Health, 16, 565-582. DOI: 10.1080/08870440108405527

Stalker, C. A., Mandell, D., Frensch, K. A., Harvey, C., \& Wright, M. (2007). Children welfare workers who are exhausted yet satisfied with their jobs: How do they do it? Child \& Family Social Work, 12(2), 182-191. DOI:10.1111/j.1365-2206.2006.00472.x

Steiger, J. H. (1990). Structural model evaluation and modification: An interval estimation approach. Multivariate Behavioral Research, 25(2), 173-180.

Steiger, J.H. (2007). Understanding the limitations of global fit assessment in structural equation modelling. Personality and Individual Differences, 42 (5), 893-98. DOI:10.1016/j.paid.2006.09.017 Stevens, G, and O’Neill, P (1983). Expectations and burnout in the developmental disabilities field. American Journal of Community Psychology, 11, 615-627

Tham, P., \& Meagher, G. (2009). Working in human services: How do experiences and working conditions in child welfare social work compare? British Journal of Social Work, 39(5), 807-827. DOI:10.1093/bjsw/bcm 170

Tucker, L. R., \& Lewis, C. (1973). A reliability coefficient for maximum likelihood factor analysis. Psychometrika, 38, 1-10. DOI: 10.1007/BF02291170

Tyler, T, (2009). Why people obey the law. New Haven, CT: Yale University Press. ISBN 13.978$0-691-12673-9$

Wagnild G, (2009a). A Review of the Resilience Scale, Journal of Nursing Management. 17, (2). DOI: $10.1891 / 1061-3749.17 .2 .105$

Wagnild, G. (2009b).The Resilience Scale user's guide for the US English version of the Resilience Scale and the 14-item Resilience Scale (RS-14).Worden, MT: Resilience Center.

Wagnild, G, and Young, H, (1993) Development and psychometric evaluation of the Resilience Scale. Journal of Nursing Measurement, 1(2), 165-78. PMID: 7850498 
Walster, E, Berscheid, E, and Walster, G, (1973). New Directions in Equity Research. Journal of Personality and Social Psychology, 25, 151-176. DOI: 10.1037/h0033967

World Health Organization. (WHO, 1992). The ICD-10 classification of mental and behavioural disorders: Clinical description and diagnostic guidelines. Geneva, Switzerland.

http://www.who.int/iris/handle/10665/37958\#sthash.2ySbQ5d2.dpuf

Figure 1. Standardised path coefficients for amended Two Process Model (Leiter 2008).

Figure 2a. Standardised path coefficients of an extended version 1 of the Two Process Model of the relationships between resilience, perceptions of aspects of work and burnout.

Figure $2 \mathrm{~b}$. Standardised path coefficients of an extended version 2 of the Two Process Model of the perceptions of aspects of work, resilience and burnout. 
Table 1 - Response Rates across Participating Organizations ( $\mathrm{n}=162)$

\begin{tabular}{llll}
\hline HSC Trust & $\begin{array}{l}\text { Potential } \\
\text { Participants }\end{array}$ & $\begin{array}{l}\text { Actual } \\
\text { Participants }\end{array}$ & \% Response Rate \\
\hline A & 90 & 37 & $41 \%$ \\
B & 72 & 33 & $46 \%$ \\
C & 76 & 28 & $39 \%$ \\
D & 59 & 22 & $37 \%$ \\
E & 64 & 24 & $38 \%$ \\
Voluntary Sector & 19 & 18 & $95 \%$ \\
Total & 380 & 162 & $43 \%$ \\
\hline
\end{tabular}

NB: To protect confidentiality of participating organizations the true identity is replaced with a label as above. 
Table 2 Means, Standard Deviations, Internal Reliability, Coefficients and Pearson Correlation matrix of Resilience, MBI and AWLS subscales (N=162).

\begin{tabular}{|c|c|c|c|c|c|c|c|c|c|c|c|c|}
\hline & Mean & S.D. & $\begin{array}{l}\text { Cronbach's } \\
\text { alpha }\end{array}$ & $\begin{array}{c}2 \\
\text { Exhaustion }\end{array}$ & \begin{tabular}{l}
\multicolumn{1}{c}{3} \\
Depersonal \\
-isation
\end{tabular} & $\begin{array}{l} \\
\text { Personal } \\
\text { Accomplishment }\end{array}$ & $\begin{array}{c}5 \\
\text { Workload }\end{array}$ & $\begin{array}{c}6 \\
\text { Control }\end{array}$ & $\begin{array}{c}7 \\
\text { Reward }\end{array}$ & $\begin{array}{c}8 \\
\text { Community }\end{array}$ & $\begin{array}{c}9 \\
\text { Fairness }\end{array}$ & $\begin{array}{c}10 \\
\text { Values }\end{array}$ \\
\hline 1 Resilience & 79.47 & 9.78 & .90 & $-.37 * *$ & -.10 & $.52 * *$ & $.21 * *$ & $.22 * *$ & .13 & .12 & .07 & $.22 * *$ \\
\hline 2. Exhaustion & 24.26 & 10.62 & .90 & & $.38^{* *}$ & $-.33^{* *}$ & $-.62 * *$ & $-.39 * *$ & $-.35^{* *}$ & -.07 & $-.24 * *$ & $-.37 * *$ \\
\hline 3. Depersonalisation & 4.57 & 2.72 & .75 & & & $-.25^{* *}$ & $-.26 * *$ & $-.19^{* *}$ & -.12 & -.08 & -.09 & $-.21 * *$ \\
\hline 4. Personal Accomplishment & 32.83 & 7.13 & .78 & & & & $.35 * *$ & $.32 * *$ & $.30 * *$ & .09 & $.20 *$ & $.25^{* *}$ \\
\hline 5. Manageable Workload & 2.14 & 0.76 & .84 & & & & & $.43 * *$ & $.39 * *$ & $.17^{*}$ & $.22 *$ & $.27 * *$ \\
\hline 6. Control & 2.98 & 0.80 & .68 & & & & & & $.44 * *$ & $.33 * *$ & $.32 * *$ & $.28 * *$ \\
\hline 7. Reward & 3.12 & 0.91 & .91 & & & & & & & $.40^{* *}$ & $.51 * *$ & $.44 * *$ \\
\hline 8. Community & 3.81 & 0.74 & .87 & & & & & & & & $.44 * *$ & $.25 * *$ \\
\hline 9. Fairness & 3.09 & 0.66 & .77 & & & & & & & & & $.40^{* *}$ \\
\hline 10.Values & 3.31 & 0.64 & .74 & & & & & & & & & \\
\hline
\end{tabular}

Note: $* \mathrm{p}<0.01, * * \mathrm{p}<0.05$. (2 tailed probability). 
Table 3

Fit Indices for various mediated path models predicting Emotional Exhaustion, Depersonalisation and Personal Accomplishment. ( $\mathrm{N}=162)$

\begin{tabular}{lccccccc}
\hline Models & $\mathrm{X}^{2}$ & $\mathrm{Df}$ & $p$ & $\begin{array}{l}\text { RMSEA } \\
(90 \% \mathrm{CI})\end{array}$ & CFI & NNFI & SRMR \\
\hline $\begin{array}{l}\text { Original } \\
\text { Two-Process }\end{array}$ & 31.59 & 12 & $<.01$ & $.10(.06-.14)$ & .91 & .85 & .10 \\
$\begin{array}{l}\text { Amended Two } \\
\text { Process } \\
\text { (version 1) }\end{array}$ & 18.99 & 11 & .06 & $.07(.00-.12)$ & .96 & .93 & .07 \\
$\begin{array}{l}\text { Amended } \\
\text { Two Process } \\
\text { (version 2) }\end{array}$ & 19.99 & 12 & .07 & $.06(.00-.11)$ & .96 & .94 & .07 \\
$\begin{array}{l}\text { Extended } \\
\text { Two Process } \\
(\text { version 1) }\end{array}$ & 38.96 & 27 & .06 & $.06(.00-.09)$ & .97 & .95 & .06 \\
$\begin{array}{l}\text { Extended } \\
\text { Two Process } \\
\text { (version 2) }\end{array}$ & 35.61 & 28 & .15 & $.04(.00-.08)$ & .98 & .97 & .05 \\
\hline
\end{tabular}

Note: RMSEA=Root Mean Squared Error of Approximation; CFI=Comparative Fit Index; NNFI=Non-Normed Fit Index; SRMR= Standardised Root Mean Residual; CI=confidence interval 
Table 4

Explained variation $\left(R^{2}\right)$ in Burnout, Aspects of Work Life and Resilience subscales from path models

\begin{tabular}{lccc}
\hline Constructs & $\begin{array}{c}\text { Amended } \\
\text { Two Process } \\
\text { model }\end{array}$ & $\begin{array}{c}\text { Two Process Model } \\
\text { (version 1) }\end{array}$ & $\begin{array}{c}\text { Extended } \\
\text { Two Process Model } \\
\text { (version 2) }\end{array}$ \\
\hline Emotional Exhaustion & .40 & .45 & .45 \\
Depersonalisation & .14 & .14 & .14 \\
Personal Accomplishment & .15 & .33 & .33 \\
Workload & .18 & .23 & .23 \\
Fairness & .10 & .32 & .32 \\
Values & .16 & .23 & .23 \\
Control & - & .22 & .19 \\
Resilience & - & - & .07 \\
\hline
\end{tabular}




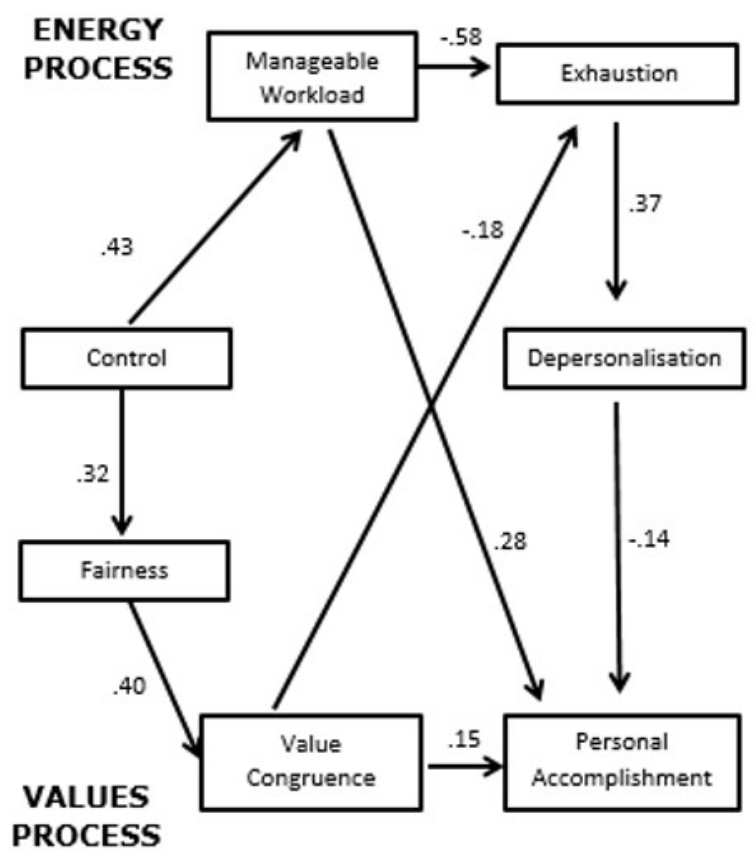

Figure 1

Standardised path coefficients for amended Two Process Model (Leiter, 2008) 


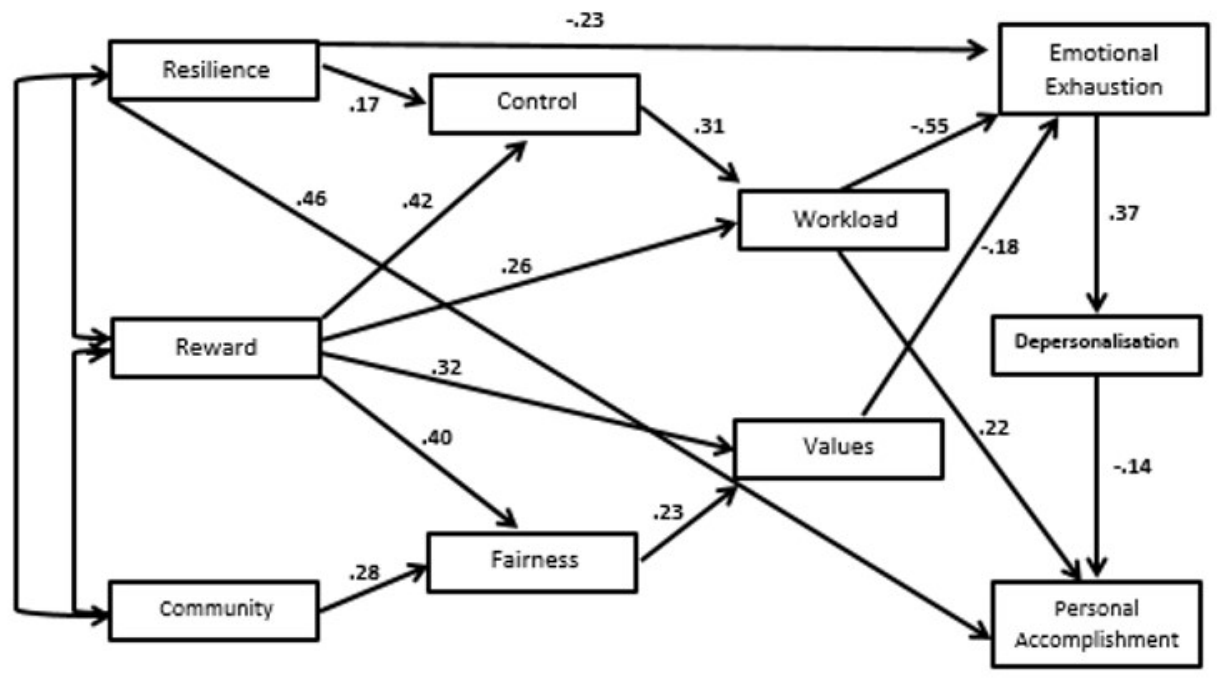

Figure 2a

Standardised path coefficients of an extended version 1 of the Two-Process Model of the relationships between resilience, perceptions of aspects of work and burnout. 


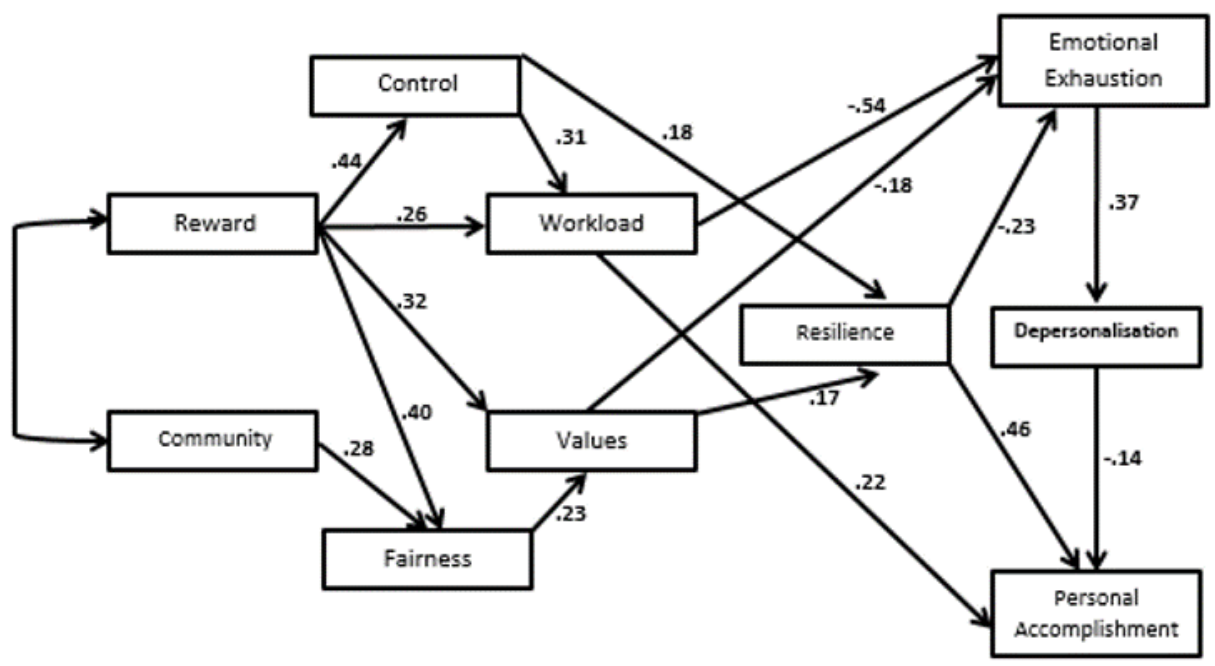

Figure $2 \mathrm{~B}$

Standardised path coefficients of an extended Two-Process model of the relationships between, perceptions of aspects of work, resilience and burnout. 